This document is published in:

L. Bolzoni, E.M. Ruiz-Navas, E. Neubauer, E. Gordo, Inductive hotpressing of titanium and titanium alloy powders, Materials

Chemistry and Physics, 2012, 131(3), 672-679,

http://dx.doi.org/10.1016/j.matchemphys.2011.10.034

(C) Elsevier 2011 


\title{
Inductive hot-pressing of titanium and titanium alloy powders
}

\author{
L. Bolzoni a, , E.M. Ruiz-Navas ${ }^{\text {a }}$, E. Neubauer ${ }^{\text {b }}$, E. Gordo ${ }^{\text {a }}$ \\ a Department of Materials Science, Universidad Carlos III de Madrid, Avda. de la Universidad 30, 28911 Leganés, Madrid, Spain \\ ${ }^{\mathrm{b}}$ Austrian Institute of Technologies GmbH (AIT), Department of Advanced Materials and Aerospace Technologies, Seibersdorf A-2444, Austria
}

\section{A R T I C L E I N F O}

\section{Article history:}

Received 26 January 2011

Received in revised form 7 October 2011

Accepted 24 October 2011

\section{Keywords:}

Inductive hot-pressing

Powder metallurgy

Titanium

Ti-6Al-4V

Ti-3Al-2.5V

Ti-6Al-7Nb

\begin{abstract}
A B S T R A C T
Inductive hot-pressing is a field-assisted sintering process (FAST) in which an electrical current is used to enhance the densification of the powder. Inductive hot-pressing could be employed to enable titanium powder to reach a higher density in less time than the pressing and sintering process. In this study, titanium and titanium alloy powders with different features were processed by means of inductive hotpressing. The influence of processing temperature on density, microstructure, quantity of interstitial elements and hardness was investigated. Generally, practically fully dense materials were obtained without any carbon pick-up, even if the materials were in contact with the graphite matrix during processing. Nevertheless, there was an increment of the nitrogen content and some oxygen pick-up, especially for the powders with smaller particle size. Hardness is not significantly affected by the pressing temperature, but it strongly depends on the amount of interstitials.
\end{abstract}

(C) 2011 Elsevier B.V. All rights reserved.

\section{Introduction}

Titanium is a relatively new engineering material and it is principally employed in highly demanding applications related to aerospace, biomedical and chemical industries. Titanium is able to meet these demands because of its particular combination of properties, including the highest strength to density ratio, outstanding corrosion resistance, excellent biocompatibility and high strength at relatively high temperatures [1-3]. Unfortunately, titanium is an expensive metal to extract and process due to its affinity for interstitial elements such as oxygen, nitrogen and carbon. Even in small amounts, these elements can significantly affect the mechanical properties of titanium, particularly its ductility [3,4]. This aspect limits the applicability of titanium in everyday applications like the automotive industry, yet interest for this metal is increasing. Some studies have affirmed that titanium could reduce the fuel consumption and pollution by reducing the weight of the vehicle $[5,6]$.

Because of its different processing techniques, powder metallurgy (PM) could possibly lower the final cost of titanium products; most of the techniques are near-net-shape or net-shape processes, and thus machining operations are limited or unnecessary [7,8]. At this time, however, titanium and titanium alloys processed by PM cover a very small niche of the market.

Among powder metallurgy techniques, hot consolidation and hot deformation processes of metallic powder, which involve the

\footnotetext{
* Corresponding author. Tel.: +34 91 6249482; fax: +34 916249430.

E-mail address: lbolzoni@ing.uc3m.es (L. Bolzoni).
}

simultaneous application of pressure and temperature, result in engineering components with higher relative density, when compared with conventional sintering, or even fully dense materials [9]. Hot-pressing, the simplest of the hot consolidation techniques, consists of loading a loose powder into a graphite mold that is then placed between two punches and heated in an enclosed furnace. The most conventional heating method for hot-pressing is high-temperature resistance; however, other options are available, such as inductive hot-pressing where the heating of the powder is done by means of the surrounding graphite mold as susceptor [8]. Through the years, numerous processes that apply an external current to assist in powder consolidation have been developed, and these processes are well described [10] and reviewed elsewhere [11]. In field-assisted sintering techniques (FAST), the main differences compared with conventional hot-pressing [12] include higher heating rates, a current passing through the metallic powder, higher cooling rates and a greater applied mechanical pressure.

During the 1970s, research was conducted on the utilization of conventional hot-pressing of titanium [13-16] and titanium alloys [17-19], but these efforts were affected by the low quality powders obtained in the Kroll's process. In the last decade, additional work has been carried out to study the densification of titanium powders during conventional hot-pressing $[20,21]$ and the properties achievable by applying this technique to the Ti-6Al-7Nb alloy [22]. Alternatively, some research has also been performed on SPS of diverse titanium powders $[21,23,24]$, but no investigations were found regarding the processing of hydride-dehydride (HDH) titanium powders by the inductive hot-press process.

The aim of this work is to investigate the applicability of the inductive hot-pressing route on some $\mathrm{HDH}$ titanium and titanium 
Table 1

Chemical analysis and physical properties of the powders used to obtain the Ti-6Al-7Nb alloy (suppliers' specifications).

\begin{tabular}{|c|c|c|c|c|c|c|c|c|c|c|}
\hline \multirow[t]{2}{*}{ Material } & \multicolumn{8}{|c|}{ Element [wt.\%] } & \multirow[t]{2}{*}{ Shape } & \multirow[t]{2}{*}{ Size } \\
\hline & $\mathrm{Ti}$ & $\mathrm{Al}$ & $\mathrm{Nb}$ & $\mathrm{O}$ & $\mathrm{N}$ & $\mathrm{H}$ & $\mathrm{C}$ & $\mathrm{Fe}$ & & \\
\hline Pure Ti (HDH) & 99.6 & - & - & 0.31 & 0.008 & 0.005 & 0.007 & 0.027 & Irregular & $<75 \mu \mathrm{m}$ \\
\hline Pure $\mathrm{Al}$ (atomized) & - & 99 & - & - & - & - & - & - & Spherical & $<150 \mu \mathrm{m}$ \\
\hline $\mathrm{Nb}: \mathrm{Al}: \mathrm{Ti}(60: 35: 5)$ & $5^{a}$ & $35^{\mathrm{a}}$ & $60^{\mathrm{a}}$ & $0.15^{b}$ & $0.05^{\mathrm{b}}$ & - & $0.05^{\mathrm{b}}$ & $0.2^{\mathrm{b}}$ & Irregular & $<0.8 \mathrm{~mm}$ \\
\hline
\end{tabular}

\footnotetext{
a Mean value.

b Maximum values.
}

alloy ( $\mathrm{Ti}-6 \mathrm{Al}-4 \mathrm{~V}, \mathrm{Ti}-3 \mathrm{Al}-2.5 \mathrm{~V}$ and $\mathrm{Ti}-6 \mathrm{Al}-7 \mathrm{Nb})$ powders with different features that were made by using the two classical titanium PM approaches, blending elemental (BE) and prealloying (PA). A study was carried out to test the influence of the main parameter, the pressing temperature, on physical, chemical and mechanical characteristics such as relative density, nitrogen content and hardness.

\section{Experimental procedure}

\subsection{Production and characterization of the powders}

In this study, one titanium hydride powder $\left(\mathrm{TiH}_{2}\right)$, two elemental titanium $\mathrm{HDH}$ powders with different particle sizes, three Ti-6Al-4V powders, two Ti-3Al-2.5V powders and one Ti-6Al-7Nb powder were investigated. The titanium alloy powders processed were either purchased (the hydride powder and prealloyed powders) or produced by combining high-energy milling (HEM) and conventional blending; the details of the production and characterization of the $\mathrm{Ti}-6 \mathrm{Al}-4 \mathrm{~V}$ and $\mathrm{Ti}-3 \mathrm{Al}-2.5 \mathrm{~V}$ powders can be found elsewhere [25]. To produce the Ti-6Al-7Nb alloy, an HDH titanium powder and a $\mathrm{Nb} / \mathrm{Al} / \mathrm{Ti}(65: 35: 5)$ master alloy with particle size lower than $0.8 \mathrm{~mm}$ ( 20 mesh) were used. Properties for these materials provided by the suppliers are shown in Table 1 .

As can be seen in Table 1, the master alloy does not have either the correct proportion of alloying elements or the appropriate particle size; therefore, its particle size was reduced by HEM. During the milling, the master alloy powder was mixed with elemental aluminium powder to reach the desired $\mathrm{Al} / \mathrm{Nb}$ ratio (60:70). The milling was carried out in a Fritsch Pulverisette mill in an inert gas atmosphere (Ar) to avoid, or at least minimize, oxidation and nitridation of the powder. For the milling, a ball-to-powder weight ratio of 5:1 and 400 revolutions per minute were used. To prevent adhesion of the powder to the vessel or grinding media, a small amount of wax was added as process control agent (PCA). Samples of milled powders were drawn out of the container every 15 min and characterized in terms of particle size distribution. The optimum milling time for the desired alloying elements ratio and particle sizes of $D_{10}$ :
$4.94 \mu \mathrm{m}, D_{50}: 17.84 \mu \mathrm{m}$ and $D_{90}: 54.34 \mu \mathrm{m}$ was found to be $30 \mathrm{~min}$. To attain the final composition (Ti-6Al-7Nb), the milled master alloy powder was mixed with the correct percentage of elemental HDH titanium powder for $30 \mathrm{~min}$ in a Turbula mixer.

All the powders to be processed by inductive hot-pressing were characterized by determining the particle size distribution by laser diffraction and by measuring the content of the interstitial elements. $\mathrm{O}$ [26] and $\mathrm{N}$ [27] were measured by inert gas fusion, and $\mathrm{C}$ [28] was measured by the combustion technique. The results of these characterizations are shown in Table 2.

In Table $2, \mathrm{TiH}_{2}$ and $\mathrm{Ti}(\mathrm{SJ})$ have the same $D_{\text {max }}$, although $\mathrm{Ti}(\mathrm{SJ})$ has a wider distribution. By comparing these two powders, it is possible to study the influence of the powder production method on the sintering behavior. Alternatively, because $\mathrm{Ti}(\mathrm{GfE})$ has bigger particle size than $\mathrm{Ti}(\mathrm{SJ}), \mathrm{Ti}(\mathrm{GfE})$ was selected to study the influence of particle size on the sintering behavior. Because titanium alloy powders have different particle sizes and/or are produced by a diverse approach, it is also possible to investigate how the particle size and the powder production process of these powders affect the final properties of the titanium alloys studied. Considering chemical analysis results, $\mathrm{TiH}_{2}$ has the highest oxygen content. Most of the powders have approximately $0.4 \mathrm{wt}$.\% of oxygen, while Ti(GfE) and Ti32-MA have the lowest oxygen percentage. The nitrogen content is consistent among the powders; only $\mathrm{Ti64}-\mathrm{PA}(\mathrm{Ph})$ has a slightly higher amount. For carbon content, it is interesting to note that powders obtained by master alloy addition have much higher values due to the fabrication method in which a wax was used as a PCA during the milling of the master alloy added for alloying elemental titanium.

\subsection{Consolidation of the powders}

To carry out the consolidation, approximately $1.5 \mathrm{~g}$ of powder was loaded into a $10-\mathrm{mm}$ diameter graphite mold. After hotpressing, discs about $3.8 \mathrm{~mm}$ in height were obtained. The inductive heating press used in this process is homemade. It is composed of a stainless steel vacuum chamber, a servo-hydraulic test machine (LF 70S) capable of dynamic loads up to $70 \mathrm{kN}$ with a frequency

Table 2

Chemical analysis and particle size distribution of the powders studied.

\begin{tabular}{|c|c|c|c|c|c|c|c|c|c|}
\hline \multirow[t]{2}{*}{ Material } & \multirow[t]{2}{*}{ Production method } & \multirow[t]{2}{*}{ Shape } & \multicolumn{4}{|c|}{ Particle size analysis $[\mu \mathrm{m}]$} & \multicolumn{3}{|c|}{ Chemical analysis [wt.\%] } \\
\hline & & & $D_{\max }$ & $D_{10}$ & $D_{50}$ & $D_{90}$ & $\mathrm{O}$ & $\mathrm{N}$ & $\mathrm{C}$ \\
\hline $\mathrm{TiH}_{2}$ & - & Irregular & $<26^{\mathrm{d}}$ & 3.97 & 7.82 & 21.73 & 0.670 & 0.11 & - \\
\hline $\mathrm{Ti}(\mathrm{SJ})$ & & & $<26^{\mathrm{d}}$ & $6.19^{d}$ & $13.19^{d}$ & $24.68^{\mathrm{d}}$ & 0.450 & 0.0100 & - \\
\hline \multirow[t]{2}{*}{$\mathrm{Ti}(\mathrm{GfE})$} & $\mathrm{HDH}^{\mathrm{a}}$ & Irregular & $<75^{d}$ & 17.31 & 37.59 & 72.59 & 0.272 & 0.0159 & 0.0202 \\
\hline & $\mathrm{PA}(\mathrm{Ph})^{\mathrm{b}}$ & & $<45^{\mathrm{d}}$ & $19.7^{\mathrm{d}}$ & $36.8^{\mathrm{d}}$ & $68.7^{\mathrm{d}}$ & $0.390^{\mathrm{d}}$ & $0.0360^{\mathrm{d}}$ & $0.0320^{\mathrm{d}}$ \\
\hline \multirow[t]{2}{*}{ Ti-6Al-4V } & $\mathrm{PA}(\mathrm{SJ})^{\mathrm{b}}$ & Irregular & $<75^{\text {d }}$ & 12.67 & 31.78 & 69.44 & 0.418 & 0.0072 & 0.0124 \\
\hline & $M A^{c}$ & & $<106$ & 17.85 & 42.94 & 95.17 & 0.428 & 0.0121 & 0.1050 \\
\hline \multirow[b]{2}{*}{$\mathrm{Ti}-3 \mathrm{Al}-2.5 \mathrm{~V}$} & $\mathrm{PA}^{\mathrm{b}}$ & & $<90$ & 16.25 & 38.79 & 78.63 & 0.402 & 0.0101 & 0.0120 \\
\hline & $\mathrm{MA}^{\mathrm{c}}$ & Irregular & $<90$ & 17.22 & 39.00 & 79.65 & 0.337 & 0.0118 & 0.0666 \\
\hline $\mathrm{Ti}-6 \mathrm{Al}-7 \mathrm{Nb}$ & $\mathrm{MA}^{\mathrm{c}}$ & Irregular & $<90$ & 17.40 & 40.39 & 81.94 & 0.393 & 0.0173 & 0.0772 \\
\hline
\end{tabular}

a Hydride-dehydride.

bPrealloyed.

${ }^{\mathrm{c}}$ Master alloy.

d'Supplier's specifications. 


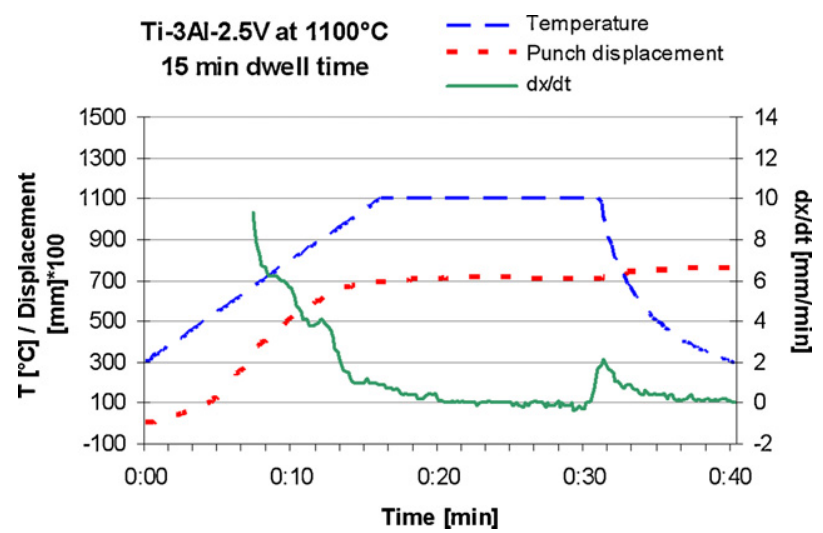

Fig. 1. A representative inductive hot-pressing cycle of the processed titanium and titanium alloy powders ( $\mathrm{Ti}-3 \mathrm{Al}-2.5 \mathrm{~V})$.

up to $70 \mathrm{~Hz}$, a strain measurement device and a self-adjusting inductive heating system with an output power of $30 \mathrm{~kW}$ and a selfoptimizing frequency $(20-150 \mathrm{kHz})$ that can heat to $2500^{\circ} \mathrm{C}$ with a heating rate of more than $50^{\circ} \mathrm{Cs}^{-1}$. The control of the temperature is done by means of a pyrometer which guarantees a precision of $\pm 5^{\circ} \mathrm{C}$.

For this study, the following parameters were used: temperatures of $1100^{\circ} \mathrm{C}$ and $1300^{\circ} \mathrm{C}$, a pressure of $50 \mathrm{MPa}$, a heating rate of $50^{\circ} \mathrm{C} \mathrm{min}^{-1}$, a dwell time at maximum temperature of $15 \mathrm{~min}$ and a vacuum level of $10^{-3}$ mbar. Fig. 1 shows an example of the inductive hot-pressing cycle used, where the total processing time is approximately $40 \mathrm{~min}$. Because of the higher heating and cooling rates, this time is much shorter than a conventional hot-pressing cycle of 6 or more hours.

In Fig. 1, the variation in height with the time $(\mathrm{d} x / \mathrm{d} t)$ starts immediately and is relatively stable within $5 \mathrm{~min}$ of reaching the maximum temperature. The variation $(\mathrm{d} x / \mathrm{d} t)$ registered just before cooling corresponds to the moment when the current is shut down, causing the specimens to cool and shrink. It should be noticed that at temperatures close to $900^{\circ} \mathrm{C}$, a peak is formed that matches the allotropic transformation from hexagonal closepacked (HCP) alpha to body-centered cubic (BCC) beta. The same peak, but more pronounced, was found when processing elemental titanium, yet it was almost imperceptible when processing the prealloyed powders. This is likely due to the prealloyed powders already containing stabilized beta, which makes up the microstructure of the powders, making the transformation less detectable. No significant differences were found in the $\mathrm{d} x / \mathrm{d} t$ graphs recorded at various temperatures. The same result was obtained by other
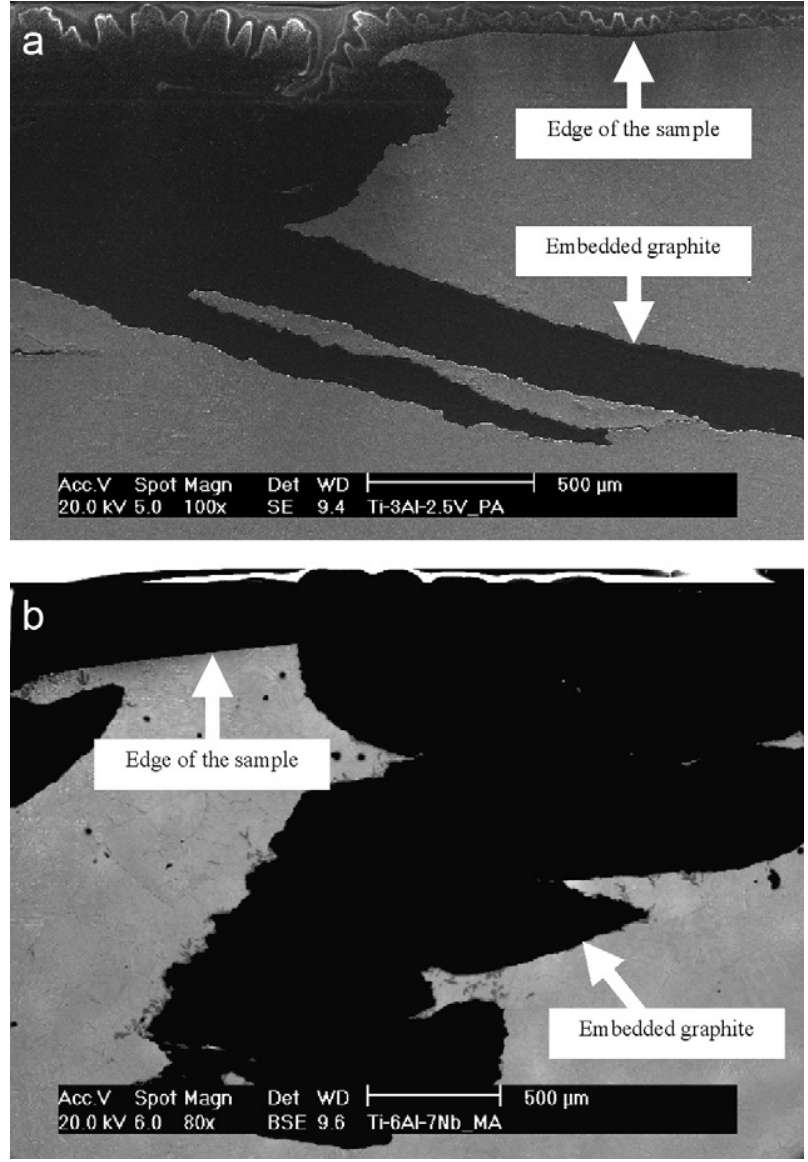

Fig. 3. Details of the surfaces of hot-pressed components where embedded graphite is clearly visible: (a) Ti32-PA processed at $1300^{\circ} \mathrm{C}$ and (b) Ti67 sintered at $1100^{\circ} \mathrm{C}$.

authors when changing the heating rate or the applied pressure [21].

Before characterization, the sintered specimens were sandblasted to clean the surfaces that had been in contact with the mold and the punches. Several tests were then performed to study the influence of the processing temperature on the properties: density measurements by means of the Archimedes' principle, oxygen [26] and nitrogen [27] content measurements by the fusion technique, carbon [28] percentage measurements by the combustion method and Vickers' hardness (HV30) tests. Microstructure analyses using optical and scanning electron microscopy were also performed.

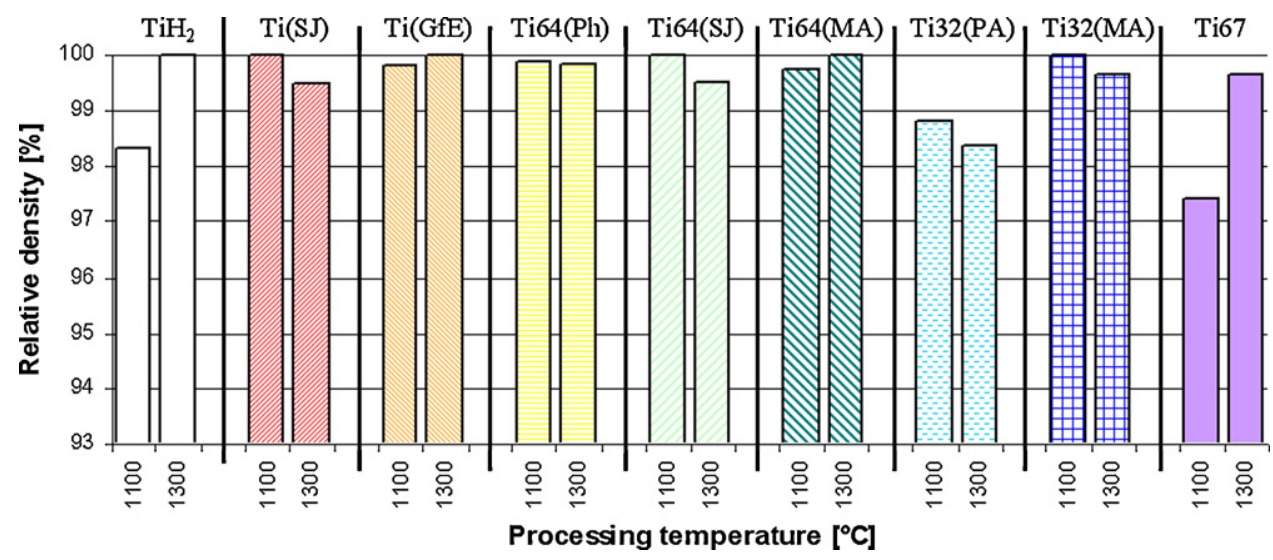

Fig. 2. Relative density results of the sintered materials processed by inductive hot-pressing at two temperatures. 


\section{Results and discussion}

The relative densities of the specimens were calculated using the nominal values of the wrought alloys $\left(4.51 \mathrm{~g} \mathrm{~cm}^{-3}\right.$ for elemental titanium, $4.48 \mathrm{~g} \mathrm{~cm}^{-3}$ for Ti-3A-2.5V, $4.43 \mathrm{~g} \mathrm{~cm}^{-3}$ for Ti-6Al-4V and $4.52 \mathrm{~g} \mathrm{~cm}^{-3}$ for Ti-6Al-7Nb), and the results are plotted versus the processing temperature in Fig. 2.

In Fig. 2, it can be seen that in most cases it is possible to produce fully dense materials. With only two of the alloys, Ti-3Al-2.5V from prealloyed powder and $\mathrm{Ti}-6 \mathrm{Al}-7 \mathrm{Nb}$, fully dense materials were not obtained; however, even in the worst case, the relative density is higher than $97 \%$, which is greater that the values normally attained with conventional PM for titanium [25]. Hot-pressing has been found to be particularly advantageous for forming parts from prealloyed powders [17]; however, from the relative densities shown in Fig. 2, the master alloyed powders seem to reach approximately the same density with the specific advantage of lower raw material cost. No appreciable influence could be found due to either the particle size or the particle size distribution.

The relative density values obtained for the Ti-6Al-7Nb alloy processed at $1100^{\circ} \mathrm{C}$, which is the lowest value of all the materials studied, and the low relative density of Ti-3Al-2.5V pressed at $1300^{\circ} \mathrm{C}$ are not due to the intrinsic nature or behavior of the powder or to the alloy composition. These low values are due to an inaccurate preparation of the graphite matrix, which led to the embedding of some graphite into the surface of the specimens. An analysis of the surfaces of the specimens by SEM, shown in Fig. 3, demonstrates this embedded graphite.

Microstructure analysis of the processed materials was carried out with both an optical microscope and a SEM. Examples of the microstructure for each material pressed at $1100^{\circ} \mathrm{C}$ and $1300^{\circ} \mathrm{C}$, both titanium and titanium alloys, are shown in Fig. 4 . To carry out the microstructure analysis, the specimens were cut, embedded into a resin, grinded with silicon carbide paper (320), polished with alumina $(9 \mu \mathrm{m})$ and silica solutions and etched by means of Kroll's reactant.

Microstructural analysis reveals that elemental titanium processed either at $1100^{\circ} \mathrm{C}$ or at $1300^{\circ} \mathrm{C}$ (Fig. 4a) is characterized by a highly heterogeneous microstructure with plate-like grains independently of particle size, particle size distribution or interstitial elements of the starting powders. This distortion from the original shape of the alpha grains conventionally found when cooling titanium from the temperatures mentioned above is thought to be due to the combined effects of the following: the application of a uniaxial pressure during the processing of the material in the beta phase, where the BCC lattice is less dense than the HCP lattice; the presence of interstitial elements; and the high cooling rate, which characterizes inductive hot-pressing. It can be seen in Fig. 4a that the microstructure of elemental titanium resembles that of CP-Ti powder obtained by plasma atomization [29]. This
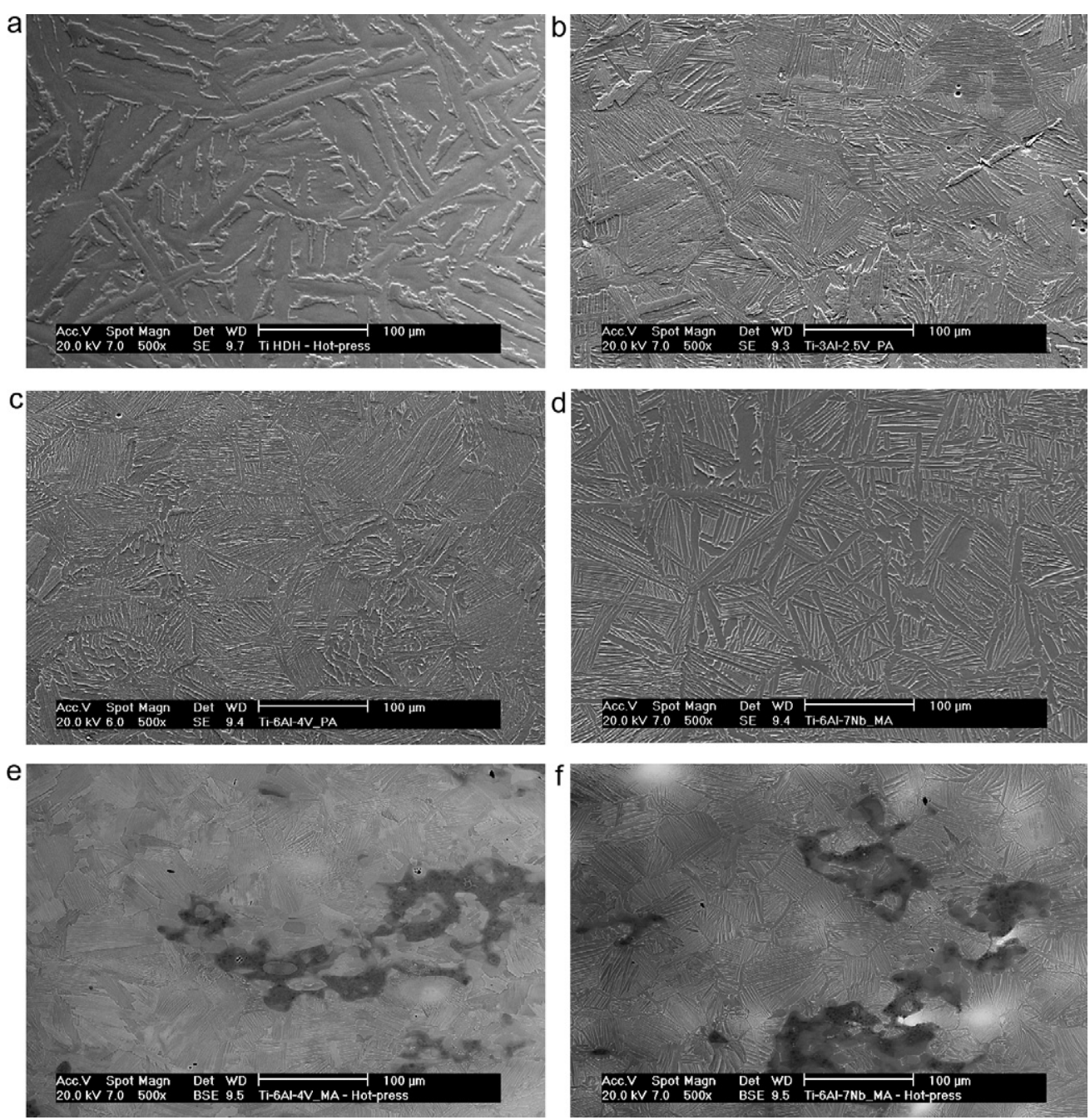

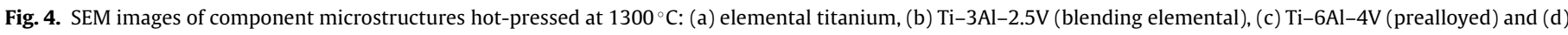
Ti-6Al-7Nb (master alloy); or at $1100^{\circ} \mathrm{C}$ : (e) Ti-6Al-4V (master alloy) and (d) Ti-6Al-7Nb (master alloy). 
Table 3

EDS chemical composition of Ti64-MA and Ti67-MA hot-pressed at $1100^{\circ} \mathrm{C}$ and $1300^{\circ} \mathrm{C}$.

\begin{tabular}{|c|c|c|c|c|c|c|}
\hline \multirow[t]{3}{*}{ Temperature $\left[{ }^{\circ} \mathrm{C}\right]$} & \multicolumn{3}{|c|}{ Ti64-MA } & \multicolumn{3}{|c|}{ Ti67-MA } \\
\hline & \multicolumn{3}{|c|}{ Composition [wt.\%] } & \multicolumn{3}{|c|}{ Composition [wt.\%] } \\
\hline & $\mathrm{Ti}$ & $\mathrm{Al}$ & V & $\mathrm{Ti}$ & $\mathrm{Al}$ & $\mathrm{Nb}$ \\
\hline 1100 & 90.39 & 7.58 & 2.03 & 85.66 & 8.60 & 5.74 \\
\hline 1300 & 89.7 & 6.56 & 3.65 & 86.53 & 6.42 & 7.05 \\
\hline
\end{tabular}

microstructure is composed of large regions containing packets of small, almost parallel $\alpha$ plates or laths (with thicknesses of approximately $0.5-1 \mu \mathrm{m}$ ) most likely corresponding to massive martensite [1] due to the high cooling rate intrinsic of this production method. Similar results, where the microstructure of CP-Ti has a distorted shape resulting in many irregular and plate-like grains, were found by other authors when using SPS to sinter titanium powder [23].

Notably, for $\mathrm{TiH}_{2}$ powder processed at $1100^{\circ} \mathrm{C}$ the microstructure is composed of fine needle-like grains of alpha titanium (see Fig. 5).

Analyzing the microstructure shown in Fig. 5, it seems that some grain boundaries of the prior-beta grains can still be identified. The grain labeled in Fig. 5 has a length of approximately $50 \mu \mathrm{m}$ and, therefore, somewhat larger than the original $D_{\max }$ which was $26 \mu \mathrm{m}$. The formation of fine whisker-like alpha titanium grains with different orientations both inside the grain and throughout the whole microstructure could be due to the compressive mechanical stress induced on the material by the uniaxial pressure applied. Nevertheless, contributions from interstitial elements should not be forgotten. It is well known that nitrogen promotes the formation of needles of alpha titanium [30] and oxygen refines the structure, making the plates of alpha titanium smaller and the Widmanstätten more regular [30].

The Ti-3Al-2.5V microstructure in Fig. $4 \mathrm{~b}$ is typical for this alloy, but, in the case of the master alloy, it seems that the final grain size is somewhat smaller. Regarding the Ti-6Al-4V and Ti-6Al-7Nb powders, with example microstructures shown in Fig. $4 \mathrm{c}$ and $\mathrm{d}$, respectively, the microstructures obtained are composed by alpha grains and $\alpha+\beta$ acicular grains. They are similar both in terms of grain size and residual porosity, independent of the particle size of the starting powder or the process employed for the production of the powder. It is worth mentioning that the microstructure of the specimens made out of master alloy powders and hot-pressed at $1100{ }^{\circ} \mathrm{C}$ resembles that of the specimens pressed at $1300^{\circ} \mathrm{C}$. However, due to the short processing time, not full chemical

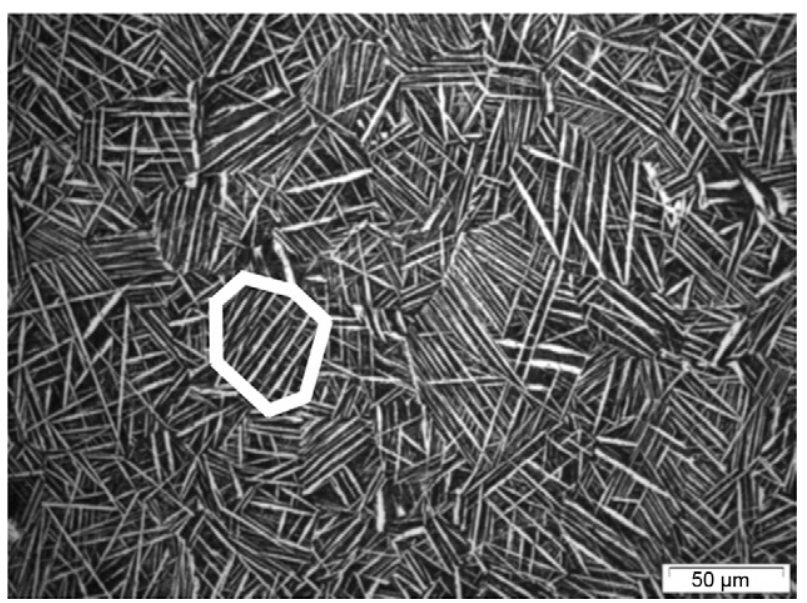

Fig. 5. Microstructure of $\mathrm{TiH}_{2}$ hot-pressed at $1100^{\circ} \mathrm{C}$ obtained with an optical microscope. homogenization is achieved as Fig. 4e and f, which shows respectively the micrograph of Ti64-MA and Ti67-MA hot-pressed at $1100^{\circ} \mathrm{C}$, demonstrate. The chemical composition of the specimens was checked by means of EDS analysis. As representative example, the results of the global composition of Ti64-MA and Ti67-MA specimens are reported in Table 3.

As it can be seen in Table 3, the EDS analysis results corroborate that at $1100^{\circ} \mathrm{C}$ the diffusion of the alloying elements in the master alloy addition powders is not completed. In particular, the percentage of aluminium is higher and that of vanadium or niobium lower than the nominal value due to the faster diffusion of aluminium compared to either vanadium or niobium. On the other side, the global composition of the specimens hot-pressed at $1300^{\circ} \mathrm{C}$ falls within the limits specified for the ASTM grade 5 and ASTM F1295 alloys [3], respectively.

The results of the chemical analysis, precisely oxygen, nitrogen and carbon content results are plotted in Figs. 6-8, respectively.

In Fig. 6, some oxygen pick-up can be seen, especially for the powders with smaller particle size, $\operatorname{Ti}(\mathrm{SJ})$ and $\mathrm{Ti64}(\mathrm{Ph})$, due to the higher specific area of the powder particles. There seems to be no significant dependence on the processing temperature because in some cases oxygen content is higher at $1100^{\circ} \mathrm{C}$ than at $1300^{\circ} \mathrm{C}$ or it remains constant for both temperatures.

Fig. 7 shows that there was nitrogen pick-up during the processing, likely due to the level of vacuum inside the processing chamber or to the handling of the powder. Moreover, the amount of nitrogen always increases with the pressing temperature, confirming that higher thermal energy available in the system results in faster diffusion of the nitrogen through the titanium matrix [31].

As it can be seen in Fig. 8, carbon content increases with the processing temperature, with the exception of Ti(SJ), most probably due to some carbon pick-up from the carbon rich atmosphere generated by the graphite tools at high temperature [9]. It is worth mentioning that the high carbon content found in Ti-3Al-2.5V processed at $1300^{\circ} \mathrm{C}(0.51 \mathrm{wt} . \%)$ and $\mathrm{Ti}-6 \mathrm{Al}-7 \mathrm{Nb}$ alloy pressed at $1100^{\circ} \mathrm{C}(2 \mathrm{wt} . \%)$ is mainly due to the graphite embedded into the surface of the specimens (Fig. 3).

Fig. 9 shows HV30 hardness test results, where each value displayed is the mean value of three measurements taken along the cross-section of the polished specimens.

As shown in Fig. 9, hardness is not significantly affected by the processing temperature because, even if in some cases increase and others decrease, the differences range between 5 and 20 HV30. This is likely due to the fact that the relative density obtained for each material at the processing conditions studied did not vary significantly. Furthermore, even if nitrogen pick-up occurs and this element hardens titanium, there is rarely a significant difference; in some cases, even if nitrogen content increases, the hardness decreases. The markedly higher hardness found in elemental titanium hot-pressed at $1100^{\circ} \mathrm{C}$ starting from a $\mathrm{TiH}_{2}$ powder compared with the same material sintered at $1300^{\circ} \mathrm{C}$ is mainly due to the heterogeneous microstructure constituted by fine whisker-like alpha titanium grains (see Fig. 5). From Fig. 9 it can be noticed that the hardness of hot-pressed specimens is, generally $30 \mathrm{HV}$ higher compared to the values of the respective wrought alloys, with the exception of $\mathrm{Ti}(\mathrm{GfE})$. These differences are likely due to the greater 


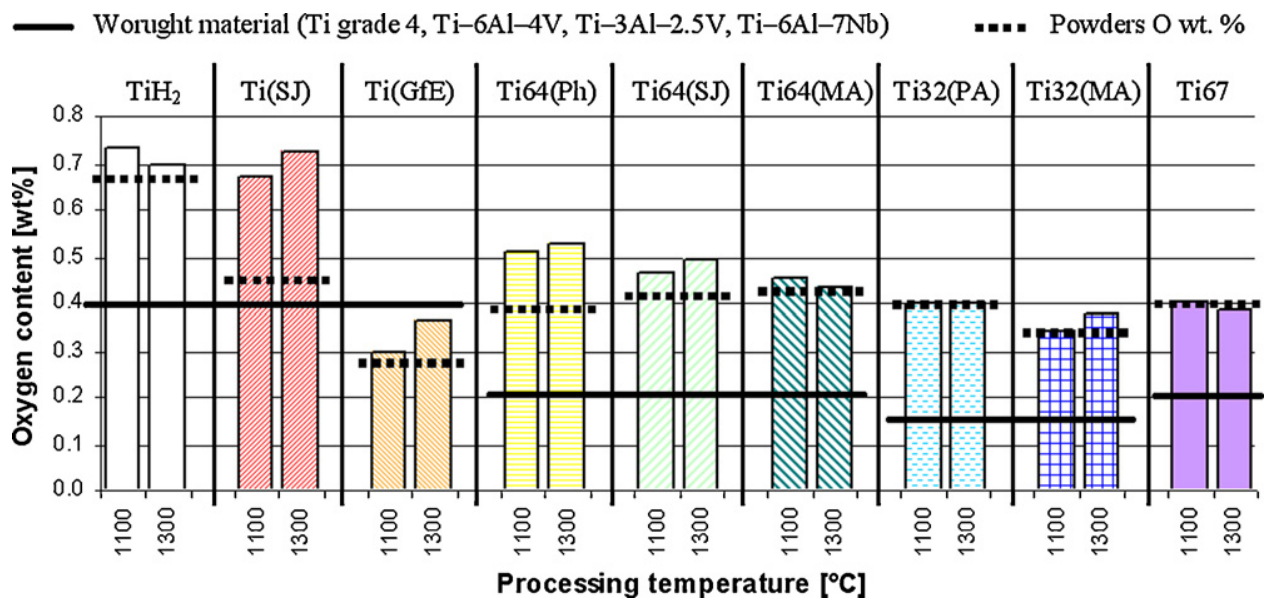

Fig. 6. Oxygen content of the samples processed by hot-pressing compared with both the content of the starting powders and that of wrought materials.

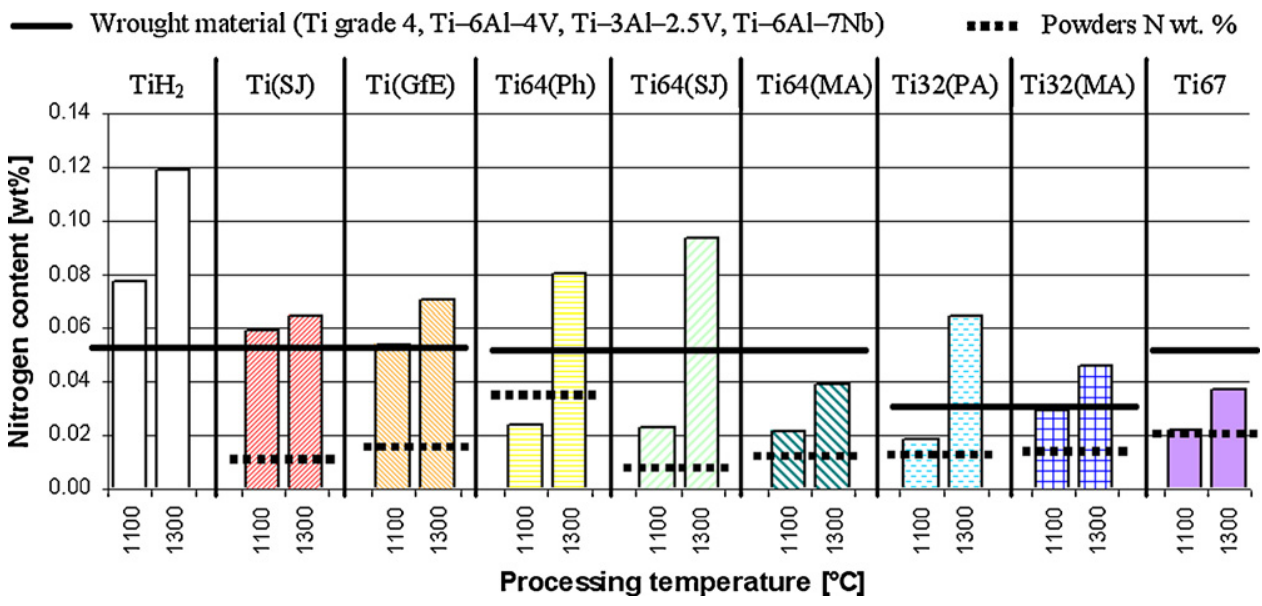

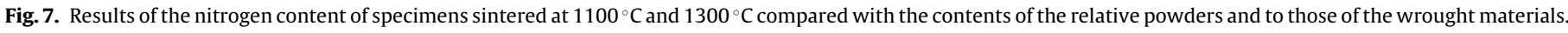

amount of interstitial elements found in the hot-pressed samples, but could also have a small contribution from the microstructural features.

Hardness measurements seem to follow the same trend of oxygen content. For the same type of material, such as elemental titanium, a higher oxygen percentage results in higher hardness. Even if it has been stated by some authors that nitrogen has the greatest hardening effect $[30,32,33]$, it seems that it is oxygen that has the greatest hardening effect on titanium and titanium alloys. To better understand the influence of the interstitial elements on the hardness of hot-pressed titanium and titanium alloys, the equivalent oxygen content was calculated based on the equation proposed by Okazaki and Conrad [34]. The results of this calculation are shown in Fig. 10.

Fig. 10 shows a good linear correlation between the hardness and the equivalent oxygen content for each of the following

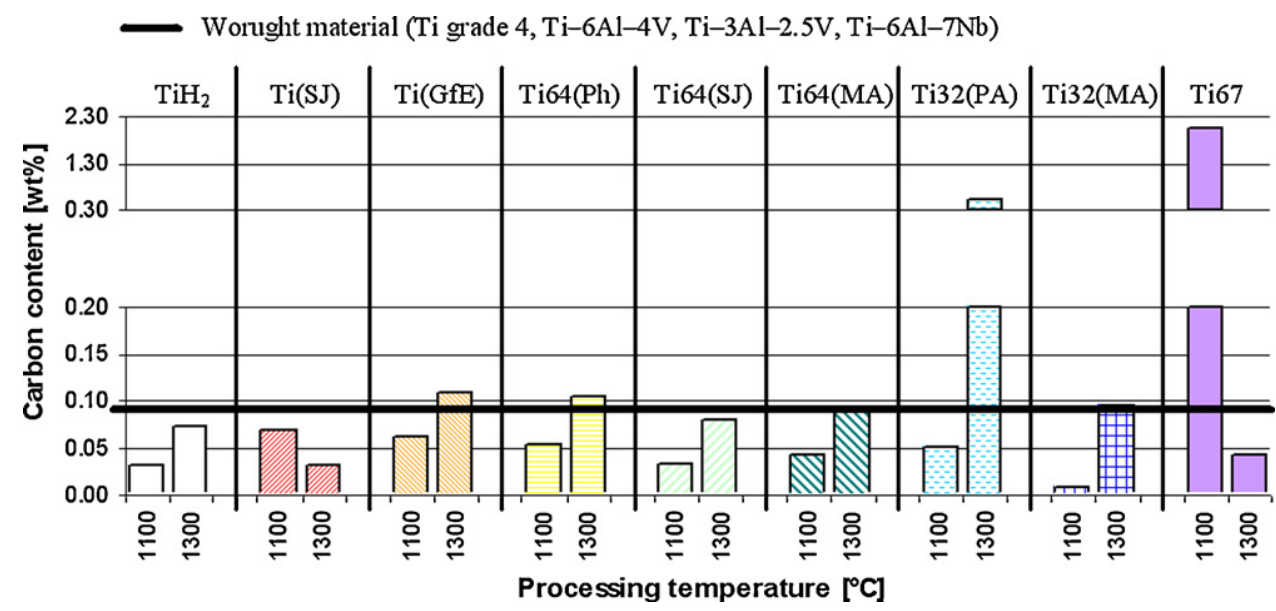

Fig. 8. Carbon content measured on inductive hot-pressed titanium and titanium alloys specimens as a function of the processing temperature. 


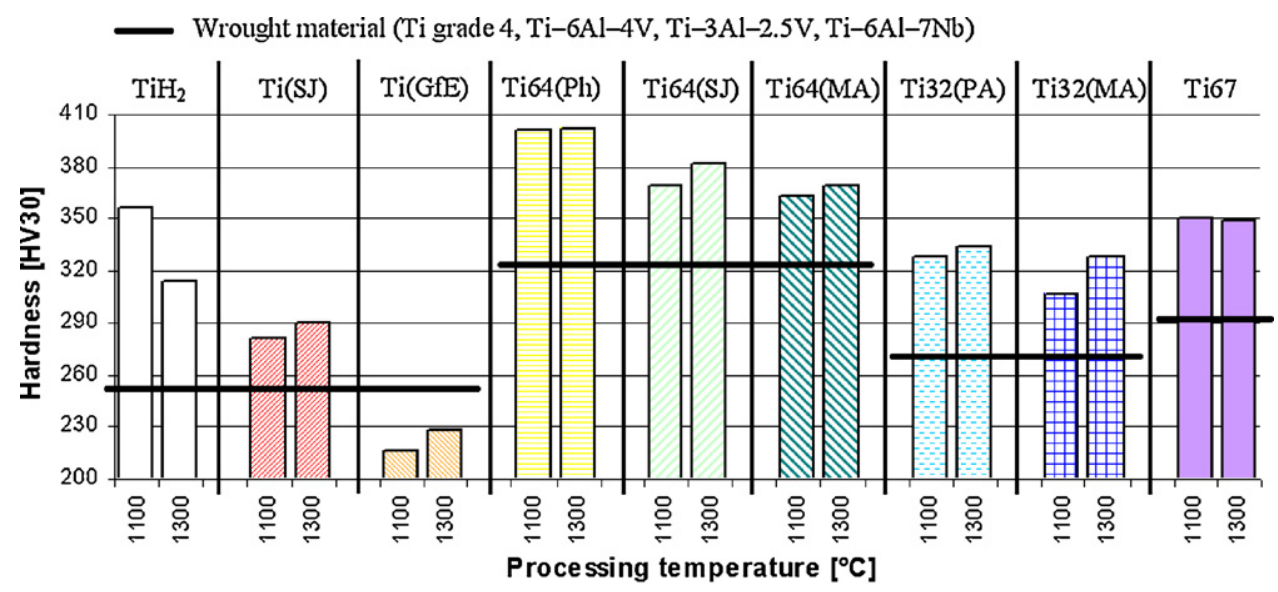

Fig. 9. Hardness (HV30) of titanium and titanium alloys processed by inductive hot-pressing and nominal values for the wrought material.
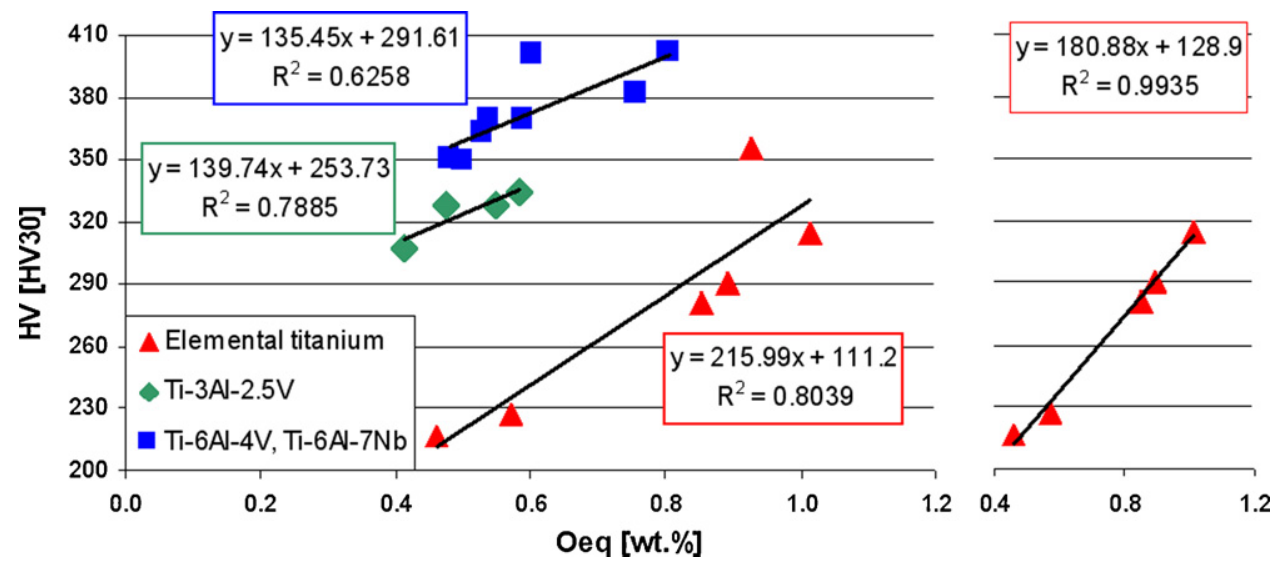

Fig. 10. Vickers' hardness versus equivalent oxygen content for hot-pressed elemental titanium, near-alpha and alpha + beta titanium alloys.

alloys processed: elemental titanium, near-alpha alloys (Ti32-PA and Ti32-MA) and alpha + beta alloys (Ti64-Ph, Ti64-SJ, Ti64-MA and Ti67). Because the hot-pressed components are practically fully dense, the deviation from linearity is mainly due to the microstructural features, such as the mean grain size and the relative percentage and morphology of the microconstituents, which are not considered when calculating the equivalent oxygen content. This could be clearly visible considering the data of elemental titanium (Fig. 10), which is made up exclusively of the alpha phase, where the only microstructure feature would be the grain size. When the anomalous value, corresponding to elemental titanium hot-pressed at $1100^{\circ} \mathrm{C}$ starting from a $\mathrm{TiH}_{2}$ powder (Fig. 5), is taken out, a perfect linear relation between $\mathrm{HV}$ and $\mathrm{O}_{\mathrm{Eq}}$. with a coefficient of determination $R^{2}$ greater than 0.99 is found (see Fig. 10). If the hardness data of the diverse materials studied are analyzed together, independent of the titanium alloy type, a poor correlation with the equivalent oxygen content is found. This further proves the influence of the microstructure, whose constituents greatly depend on the amount of alloying elements and their stabilizing effects ( $\alpha$ or $\beta$ stabilizer), on the variation of the hardness from a linear correlation with the equivalent oxygen content.

\section{Conclusions}

This study confirms that field-assisted sintering processes, such as inductive hot-pressing, could be used to produce fully dense titanium and titanium alloys products. Furthermore, this process could be employed starting from the more economical master alloyed powders but care must be taken in order to achieve the complete diffusion of the alloying elements.

With few exceptions, it seems that the temperature in the range investigated does not significantly affect the density, but it is notable that the $\mathrm{TiH}_{2}$ hot-pressed at $1100^{\circ} \mathrm{C}$ is characterized by a particular microstructure derived from the stabilization of the alpha titanium needle-like Widmanstätten structure triggered by the applied pressure and the interstitial elements dissolved inside the matrix.

The chemical analysis revealed that some oxygen, nitrogen and carbon pick-up occurred, especially in powders with smaller particle sizes due to their higher specific surface area.

Hardness values do not seem to be greatly influenced by the processing temperatures used or by the relative density levels, but these values can be related to the equivalent oxygen content even if care is taken to not forget the influence from the microstructural features.

\section{Acknowledgements}

The authors are thankful for the financial support from Comunidad de Madrid through the ESTRUMAT (S-2009/MAT-1585) project and from the Spanish Ministry of Education through the R\&D MAT2009-14448 Project.

\section{References}

[1] G. Lütjering, J.C. Williams, Titanium: Engineering Materials and Processes, $1 \mathrm{st}$ ed., Springer, Manchester UK, 2003. 
[2] C. Leyens, M. Peters, Titanium and Titanium Alloys. Fundamentals and Applications, Wiley-VCH, Köln, Germany, 2003.

[3] R. Boyer, G. Welsch, E.W. Collings, Materials Properties Handbook: Titanium Alloys, ASM-International (Ed.), OH, USA, 1998.

[4] M.J. Donachie, Titanium. A Technical Guide, 2nd edition, ASM International, OH, USA, 2000.

[5] E.H. Kraft, Opportunities for Low Cost Titanium in Reduced Fuel Consumption, Improved Emissions, and Enhanced Durability Heavy-Duty Vehicles. Subcontract 4000013062, EHK Technologies, Vancouver, WA 98664, USA, 2002.

[6] C.A. Lavender, Low-cost titanium evaluation, in: F.P. Report (Ed.), Automotive Lightweighting Materials, Contractor: Pacific Northwest National Laboratory, 2004.

[7] R.M. German, Powder Metallurgy Science, 2nd edition, MPIF - Metal Powder Industries Federation, Princeton, USA, 1994.

[8] W. Schatt, K.-P. Wieters, Powder Metallurgy. Processing and Materials, EPMA - European Powder Metallurgy Association, Shrewsbury, UK, 1997.

[9] A. Bose, W.B. Eisen, Hot Consolidation of Powders \& Particulates, Metal Powder Industries Federation, Princeton, USA, 2003.

[10] J.R. Groza, A. Zavaliangos, Sintering activation by external electrical field, Materials Science and Engineering A 287 (2000) 171-177.

[11] R. Orrù, R. Licheri, A.M. Locci, A. Cincotti, G. Cao, Consolidation/synthesis of materials by electric current activated/assisted sintering, materials science and engineering R, Reports 63 (2009) 127-287.

[12] Z.A. Munir, U. Anselmi-Tamburini, M. Ohyanagi, The effect of electric field and pressure on the synthesis and consolidation of materials: a review of the spark plasma sintering method, Journal of Material Science 41 (2006) 763-777.

[13] C.G. Goetzel, V.S. de Marchi, Electrically activated pressure sintering (spark sintering) of titanium powders, Powder Metallurgy International 3 (1971) 80-87.

[14] C.G. Goetzel, V.S. de Marchi, Electrically activated pressure sintering (spark sintering) of titanium powders, Powder Metallurgy International 3 (1971) 134-136.

[15] H.Zenshiro, A. Kiyoaki, Electrical resistance of resistance-sintered titanium and its alloys, Journal of the Japan Society of Powder and Powder Metallurgy 26 (1979) 180-186.

[16] H. Zenshiro, A. Kiyoaki, Influences of sintering condition, particle size alloying powders on electric resistance-sintering process of titanium powder, Journal of the Japan Society of Powder and Powder Metallurgy 25 (1978) 198-201.

[17] C.G. Goetzel, V.S. de Marchi, Electrically activated pressure sintering (spark sintering) of titanium-aluminium-vanadium alloy powders, Modern Developments in Powder Metallurgy 4 (1971) 127-150.

[18] W.H. Kao, D. Eylon, C.F. Yolton, F.H. Froes, Effect of temporary alloying by hydrogen (HYDRO-VAC) on the vacuum hot pressing and microstructure of titanium alloy powder compacts, Progress in Powder Metallurgy 37 (1982) 289-301.
[19] R.K. Malik, Vacuum hot pressing of titanium alloy powders, Progress in Powder Metallurgy 31 (1975) 277-288.

[20] K.T. Kim, H.C. Yang, Densification behavior of titanium alloy powder under hot isostatic pressing, Powder Metallurgy 44 (2001) 41-47.

[21] M. Eriksson, Z. Shen, M. Nygren, Fast densification and deformation of titanium powder, Powder Metallurgy 48 (2005) 231-236.

[22] V.A.R. Henriques, C.E. Bellinati, C.R.M. da Silva, Production of Ti-6\%Al-7\%Nb alloy by powder metallurgy (P/M), Journal of Materials Processing Technology 118 (2001) 212-215.

[23] M. Zadra, F. Casari, L. Girardini, A. Molinari, Microstructure and mechanical properties of CP-titanium produced by spark plasma sintering, Powder Metallurgy 51 (2008) 59-65.

[24] A. Molinari, M.Zadra, Influence of the Sintering Temperature on Microstructure and Tensile Properties of Ti6Al4V Produced by Spark Plasma Sintering, EUROPM 2009, EPMA, Copenhagen, Denmark, 2009, pp. 267-272.

[25] L. Bolzoni, P.G. Esteban, E.M. Ruiz-Navas, E. Gordo, Influence of powder characteristics on sintering behavior and properties of PM Ti alloys produced from prealloyed powder and master alloy, Powder Metallurgy 54 (4) (2011) 543-550.

[26] ASTM E 1409, Standard Test Method for Determination of Oxygen in Titanium and Titanium Alloys by the Inert Gas Fusion Technique, 1997.

[27] ASTM E 1937, Standard Test Method for Determination of Nitrogen in Titanium and Titanium Alloys by the Inert Gas Fusion Technique, 1997.

[28] ASTM E 1941, Standard Test Method for Determination of Carbon in Refractory and Reactive Metals and their Alloys, 2004.

[29] L. Bolzoni, P.G. Esteban, E.M. Ruiz-Navas, E. Gordo, Influence of Titanium Powder Features on its Pressing Performance, EURO PM 2009, EMPA, Copenhagen, Denmark, 2009, pp. 229-234.

[30] R.I. Jaffee, I.E. Campbell, The effect of oxygen, nitrogen and hydrogen on iodide refined titanium, Transactions of the American Institute of Mining and Metallurgical Engineers 185 (1949) 646-654.

[31] R.J. Wasilewski, I. Kehl, Diffusion of nitrogen and oxygen in titanium, Journal Institute of Metals 83 (1954-1955) 94-104.

[32] R.I. Jaffee, H.R. Ogden, D.J. Maykuth, Alloys of titanium with carbon, oxygen and nitrogen, Transactions of the American Institute of Mining and Metallurgical Engineers 188 (1950) 1261-1266.

[33] W.L. Finlay, J.A. Snyder, Effects of three interstitial solutes (nitrogen, oxygen and carbon) on the mechanical properties of high-purity alpha titanium, Journal of Metals 188 (1950) 277-286.

[34] K. Okazaki, H. Conrad, Effect of grain size and interstitial solute content on the hardness of Ti-N, Ti-O and Ti-C alloys at room temperature, Tranactions of JIM 14 (1973) 364-367. 